\title{
Três depoimentos de artistas plásticos
}

\author{
Denise Nozaki* \\ José Vieira** \\ Nina Arbex ${ }^{* * *}$
}

\section{RESUMO}

Durante o último Seminário em diálogo com o pensamento de Paul Tillich, dedicado à relação entre religião e artes visuais, convidamos três artistas plásticos para dar um depoimento sobre o seu encontro com o Sagrado através da arte. Para Denise Nozaki, uma obra de arte é a concretização da imagem autêntica que um artista tem dentro de si. A autora expressa no quadro Malinkaya a transição menina-mulher, divino-humano, presente nela mesma. Para José Vieira, a união entre a religião e a arte leva a alcançar um estado alquímico na relação com a argila, matéria sagrada. "Durante o processo de criação, caminho no vazio e a relação com a técnica passa a ser o fio que me liga como artista ao fazer sagrado". Nina Arbex procura compartilhar a experiência da criação pictórica no âmbito do Sagrado, remetendo à Bíblia sagrada, a Paul Tillich e Rudolf Otto. Para ela, ao se apropriar do simbólico, o artista encontra o numinoso. "Buscar compreender o Sagrado passou a fazer parte de uma busca essencial não apenas no aspecto religioso, mas também no mundo do artista". Juntamos os três depoimentos num único texto. Na medida do possível, foi conservada a formatação de cada artista.

Palavras-chave: artista plástico; testemunho; religião; arte

\section{ABSTRACT}

On the last "Seminar in Dialogue with the Thought of Paul Tillich", which was dedicated to the relation between religion and visual arts, we

* Denise Aparecida Nozaki Coelho. Nome artístico: Dize Nozaki. Nascida em São Paulo, atualmente residindo em Guaratinguetá, SP.

** Graduado em artes plásticas. Mestre em ciências da religião. Professor do Instituto Arte Cerâmica (IACE) em São Paulo.

*** Pedagoga formada pela Universidade Metodista de São Paulo. Artista Plástica, formada pela Faculdade de Belas Artes de São Paulo. 
invited three artists to speak about their encounter through art with the Sacred. For Denise Nozaki, a work of art is the artist's authentic inner image concretization. The author expresses within herself in Malinkaya canvas the girl-woman transition, the divine-human human transition. For José Vieira, the union of religion and art leads to an alchemical state in contact with clay, a sacred matter. "During the creation process, I walk in the void, and my relation with technique becomes the thread that binds me as an artist in making it sacred". Nina Arbex seeks to share the experience of pictorial creation within the Sacred, referring to the sacred Bible, Paul Tillich, and Rudolf Otto. For her, in appropriating the symbolic the artist finds the numinous. "Seeking to understand the Sacred has become part of an essential search not only in the religious aspect, but also in the artist's world". We gathered the three testimonies in a single text. As far as possible, each artist formatting was preserved. Keywords: Plastic Artist; Testimony; Religion; Art

\section{Dize Nozaki, artista plástica}

Um antigo provérbio chinês diz que para pintar o bambu é necessário que primeiro ele nasça no seu coração. Isto bastaria para constatar que a arte é a expressão do que realmente temos dentro de nós, portanto, o artista exterioriza o que ele é, sente, busca e crê.

É possível que alguém pinte ou desenhe muito bem por meio de técnicas e habilidades; contudo, uma obra-prima é certamente a concretização da imagem autêntica que um artista tem dentro de si. Desta forma, a arte passa pelo campo da razão e sempre incluirá os sentimentos.

Toda tentativa e habilidade para harmonizar interior e exterior, abstrato e concreto no campo da arte abrangem perfeitamente conceitos da Teologia Cultural de Paul Tillich. As batalhas cósmicas entre divino e demônio, entre o lógico e o ilógico, humano e divino, sentimentos e razão, eu posso encontrar em uma das minhas telas pintada a óleo. 


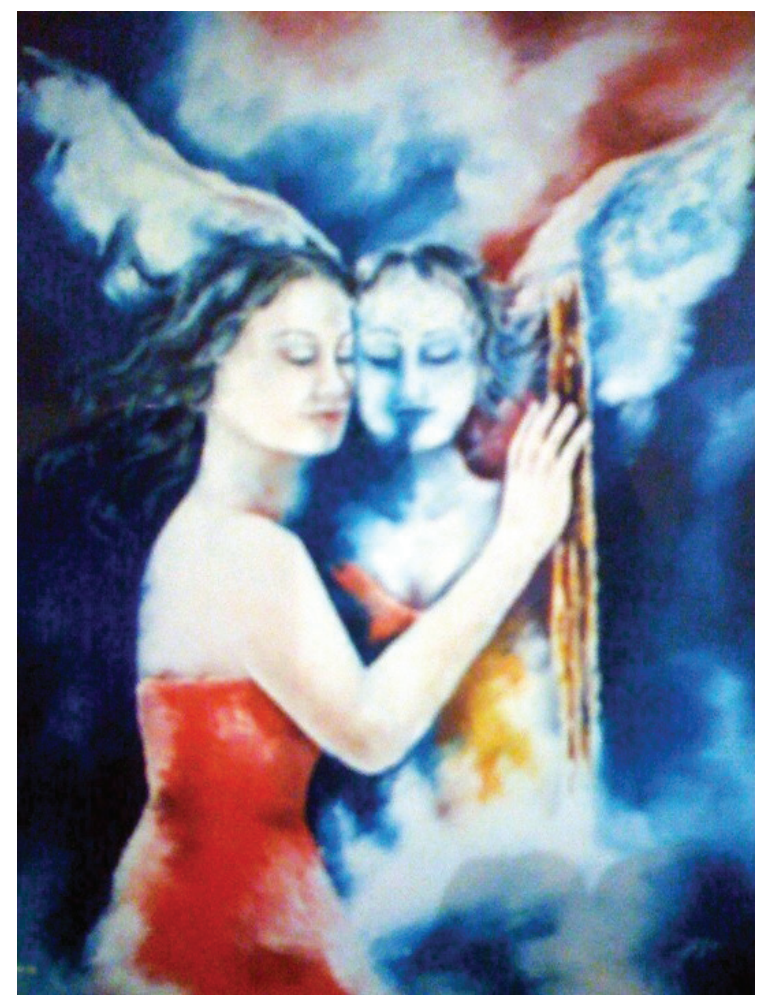

"Malinkaya" (óleo s/tela 50x60cm, 1995) foi uma expressão espontânea pintada com a ajuda dos dedos e o pincel em um tempo aproximado de vinte minutos, de madrugada. Não houve a preocupação com o desenho artístico ou geométrico, tampouco a intervenção das análises racionais que podem limitar ou bloquear a expressão do artista. Muitas vezes, ao pintar, enfrentamos um conflito interno entre o que queremos e o que achamos que as pessoas irão pensar ou sentir a respeito de nossa arte. É quase como um dualismo ou uma batalha interna assim como em Paul Tillich.

Malinkaya é a representação de uma patinadora russa que sempre teve o apoio e a presença de sua mãe em todas as suas apresentações, mas que, após a morte de sua mãe, passara a patinar com muito mais empenho com o amor sempre presente por sua mãe.

Eu sou uma artista cristã e não pintei a representação da patinadora e sua mãe já falecida, mas me comovi intensamente ao conhecer a sua história naquele dia e me levantei de madrugada para pintar. Eu expressei em Malinkaya a minha transição menina-mulher, divino-humano, presente 
em mim mesma. Em Malinkaya, eu também vejo os conceitos que recebi de minha mãe e a minha própria maneira de me ver e de me descobrir diante de Deus, da família e do mundo. Malinkaya não está necessariamente diante de um espelho refletindo a si mesma, mas a pintura reflete dois lados, duas pessoas; não necessariamente um confronto, mas um encontro com harmonia e entendimento... em uma só pessoa.

Eu me preocupo com o sentido das minhas pinturas e o que estou transmitindo através das minhas telas, e isso fortalece um vínculo hermenêutico com a Teologia da Cultura de Paul Tillich.

Eu penso que a Pintura amplia a realidade para todos os níveis uma vez que estrutura a própria alma, concretiza os sentimentos e traz o divino para perto do humano ou ainda o humano até o divino quando o torna capaz de ter sensações que vão além de suas preocupações e lógicas. É como romper com a realidade emergindo das profundezas para a superfície e alcançando sensações que não são sentidas de outra forma senão pela arte e pelo amor.

Por vezes, eu gosto de pintar usando os dedos para sentir a textura da tinta e intensificar a expressão em cada tela. Eu gosto de ouvir Beethoven e Vivaldi para pincelar ávida e alegremente o ritmo das cores e dos traços sobre a tela. Assim, eu permito que o bambu nasça dentro do meu coração para brotar concretamente no branco da tela que se transforma em arte.

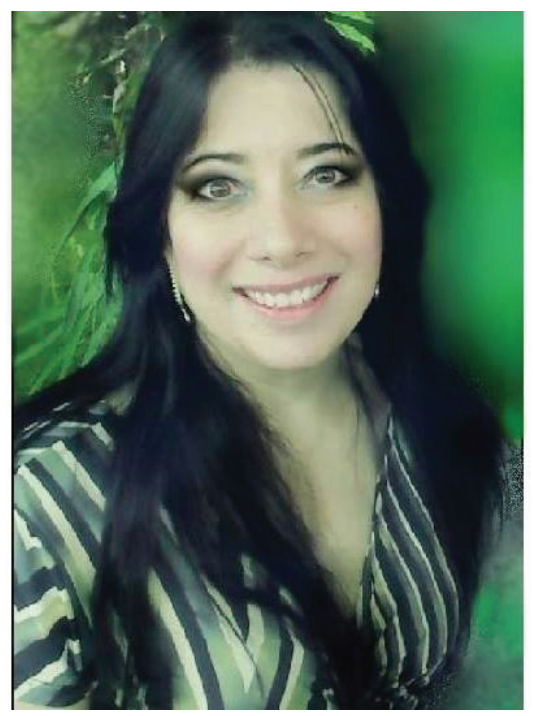




\section{José Vieira, Ceramista}

Minha formação acadêmica se deu com a graduação em artes plásticas e a pós-graduação em ciências da religião, mas meu primeiro contato com as artes se deu em Santos nos anos 1970, onde tive participação em diversos grupos de teatro amador.

No início da década de 1980, comecei a cursar a faculdade de Artes Plásticas em São Paulo e, desde o final do curso, já iniciei minha vida profissional na divisão de arte cerâmica na Fundação Mokiti Okada, conhecida hoje como Instituto Arte Cerâmica (IACE). Fui professor e exerci o cargo de coordenador do curso até 2015, ano em que passei a me dedicar exclusivamente às atividades de ensino.

Escolhi a formação em artes plásticas porque o teatro amador me proporcionou a expressão não só física e verbal, mas também dos meus sentimentos e eu queria dar continuidade a esse processo de evolução artística. Essa decisão de atuar nesse campo também contribuiu para ampliar meu caminho pela procura da minha interioridade.

A conexão que estabeleci entre a religião e a arte se deu porque percebi que a primeira tem seus dogmas e regras e a criação artística é livre. Unir as duas significou para mim encontrar a ligação entre a formalidade da religião, que me proporciona o sentimento do fazer, com a afetividade e o carinho. Essa união me levou a alcançar um estado alquímico durante a relação com o material de trabalho.

Ao percorrer esse caminho, encontrei a técnica como uma base para desenvolver minha trajetória artística e, dessa maneira aprender sempre. Ela ajuda a assimilar conceitos e a reaprender diariamente. Durante o processo de criação, caminho no vazio e a relação com a técnica passa a ser o fio que me liga como artista ao fazer sagrado. A etapa seguinte ocorre quando consigo me desprender das fases de aplicação dessa técnica de manipulação e do uso dos materiais e chego ao fazer criativo e, então, alcanço o sagrado.

No meu trabalho como professor, e ensinando também me expresso como artista, quero ensinar muito mais através das mãos do que com as palavras. Mostro aos alunos como a natureza oferece os materiais e a partir daí eles se transformam através da expressão artística e passam a criar arte. Minha missão, como professor, é a de e ensinar essa relação transcendente com a arte. 
Dentro dessa trajetória como professor percebi as transformações pelas quais os alunos passam. Elas se dão até em sua constituição física. Tento, assim, reavivar o que está adormecido nas pessoas, pois a sociedade moderna não estimula esse tipo de busca pelo autoconhecimento. Como professor minha missão é despertar esses sentimentos.

Durante os cursos e em meu trabalho criativo percebi que é fundamental ressaltar a importância da transformação que o contato com os elementos básicos da natureza, que são a terra, a água, o fogo e o ar provoca em cada um. A arte da cerâmica proporciona o uso de todos eles e o ser humano compreende que tem todos eles dentro de si no momento em que aplica as técnicas durante o processo criativo.

Em meu caminho profissional e artístico, e especialmente quando ensino, o ato de oferecer a argila ao aluno é especial e simbólico. Explico a ele que se trata de um material sagrado que pode proporcionar a oportunidade de uma transformação interior que o levará ao encontro da beleza e de outras descobertas pessoais. Essa busca depende de cada um e a produção artística através da cerâmica poderá ser despertada e criar símbolos que o conduzirão a um estado de consciência espiritual adormecida há muito tempo. Depende de cada um.

\section{Obras do artista}

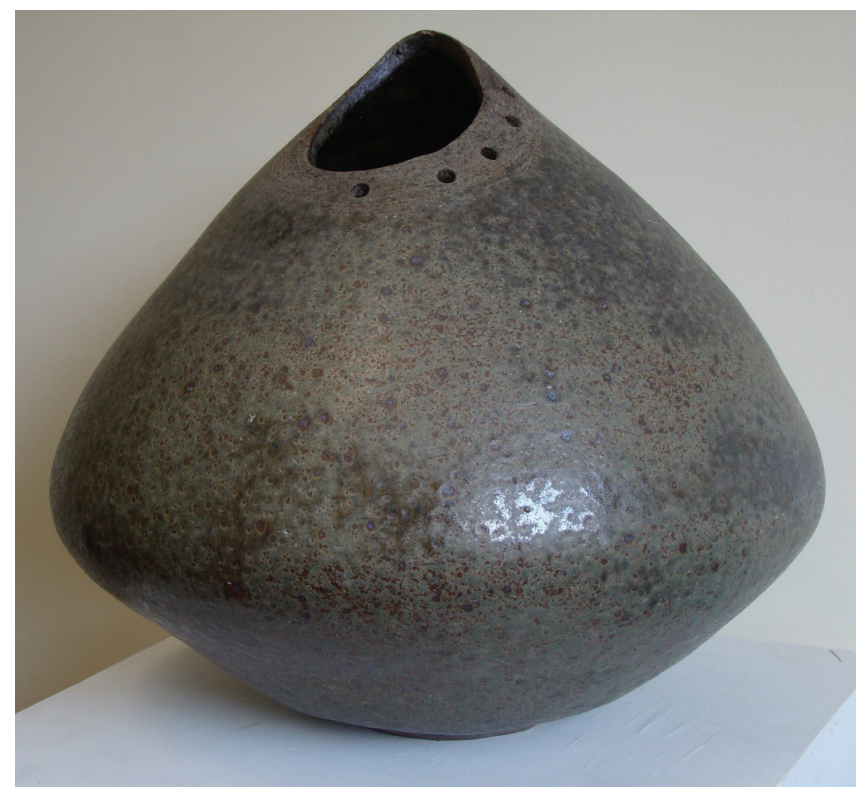




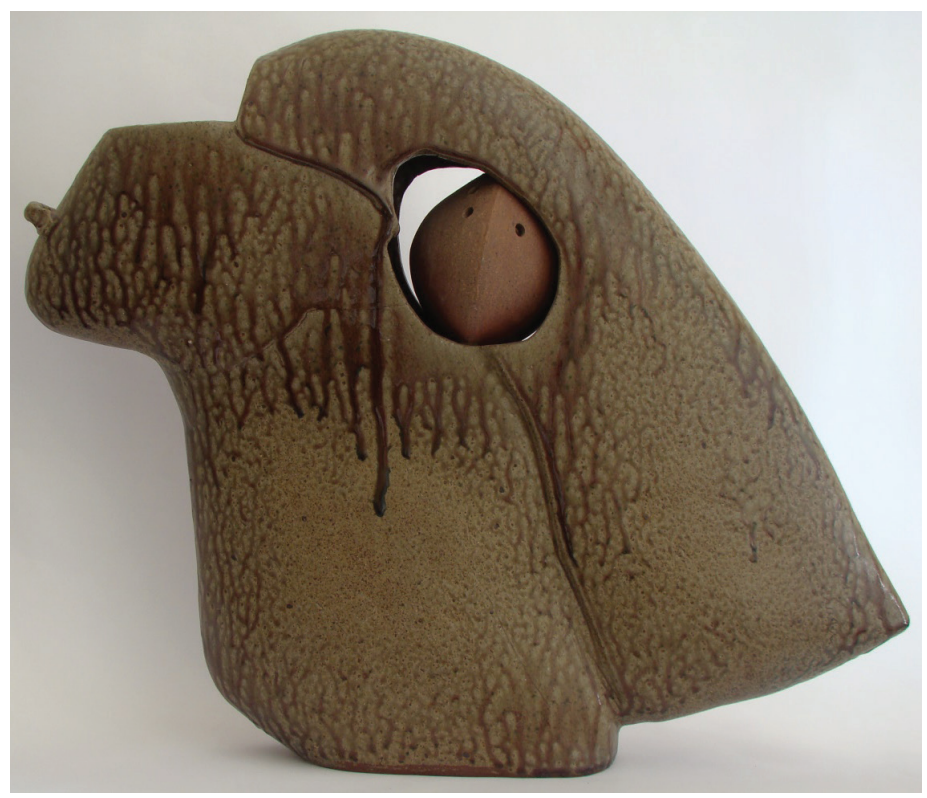

\section{Nina Arbex, pintora: Arte e Sagrado}

Procuro, neste texto, compartilhar a experiência da criação pictórica no âmbito do Sagrado, com pesquisa em Paul Tillich e Rudolf Otto, além da leitura da Bíblia Sagrada em paralelo ao estudo da Arte.

\section{Introdução}

Parece que foi ontem... Caminhando em Santos em direção à praia, numa manhã de sábado, me senti atraída pela majestosa Arquitetura de um templo "que me aguardava". Entrei com cuidado e um sentimento de reverência, como se já soubesse que ali alguém havia marcado um encontro do numinoso na minha vida, me tomou.

Depois desse dia, as luzes daquele tempo continuam a refletir no meu cotidiano.

\section{O Sentimento}

De acordo com Rudolf Otto, o numinoso é uma experiência exclusivamente religiosa. Acontece positivamente através de sentimento desencadeado na psique e porque é irracional, não pode ser claro, explícito, necessita e utiliza os sentimentos. Sua natureza é como um arrebatamento que aciona a psique humana. Nesse contexto, esses sen- 
timentos afins ou contrastantes encontram-se também mediante expressões simbólicas.

O sentimento Numinoso não é uma mera emoção, mas é um estado afetivo, um sentimento original. Não podemos defini-lo, mas está presente na consciência na vida das pessoas e expressa-se nas relações humanas (interpessoais).

\section{O Sagrado na Arte}

Como o numinoso pode ocorrer na arte ou através dela?

Ao se apropriar do simbólico, o artista pode "trazer" ao observador a noção de Numen, que é o estado compreendido como sendo o sentimento de criatura ${ }^{1}$. Reação provocada no consciente pelo sentimento de ser objeto do numinoso. Onde de certa forma, se dá o ato de reciprocidade, de ser responsivo ao sagrado.

O sentimento de ser criatura, também é um sentir-se pequeno quando se está diante de uma realidade suprema, momento em que me pergunto como artista:

Como consegui fazer isso ou aquilo? Logo me percebo diante daquela realidade suprema e sinto que criar e pintar também é um estado de alma onde a finitude "aparece" e extasiada sou atraída pelo luminoso.

Parece que foi ontem...quando me percebi sendo tocada pelo Sagrado na leitura do texto de II Coríntios 2:9 "Nem olhos viram, nem ouvidos ouviram, nem jamais penetrou em coração humano o que Deus tem preparado para aqueles que O amam". Coincidentemente, Otto cita o mesmo texto em seu livro "O Sagrado". ${ }^{2}$

Com o passar do tempo, buscar compreender o Sagrado passou a fazer parte de uma busca essencial não apenas no aspecto religioso como também no mundo da arte. Nessa busca, compreendi que o Sagrado não é realmente ensinável em sentido estrito, mas pode e deve ser estimulável, incentivado - como tudo que provem "do espírito". ${ }^{3}$

\footnotetext{
1 OTTO, Rudolf. O Sagrado: um estudo do elemento não-racional na idéia do divino e a sua relação com o racional. (tradução: Prócoro Velasquez Filho). São Bernardo do Campo: Imprensa Metodista, 1985.

2 OTTO, Rudolf. O Sagrado: um estudo do elemento não-racional na idéia do divino e a sua relação com o racional. (tradução: Prócoro Velasquez Filho). São Bernardo do Campo: Imprensa Metodista, 1985.

3 OTTO, Rudolf. O Sagrado: um estudo do elemento não-racional na idéia do divino e a sua relação com o racional. (tradução: Prócoro Velasquez Filho). São Bernardo do Campo: Imprensa Metodista, 1985.
} 
De acordo com Paul Tillich, "Quando falamos acerca de religião e arte, devemos falar em termos que digam respeito a ambos os conceitos. Quando ouvimos as palavras "arte sacra", normalmente cremos que esta se refere em particular a símbolos religiosos. Ora, este é um siginificado da arte sacra; mas há um outro que se segue de mais amplo conceito de religião, a saber, arte como a expressão de uma inquietação última. Naturalmente, esta será uma expressão estética, uma expressão artística, mas será a expressão de uma inquietação última."4

Pensando em tudo isso, reconheço minha preocupação última quando concebi o quadro "O Cenáculo".

Figura 1 “O CENÁCULO” ARBEX, Nina, 2015.

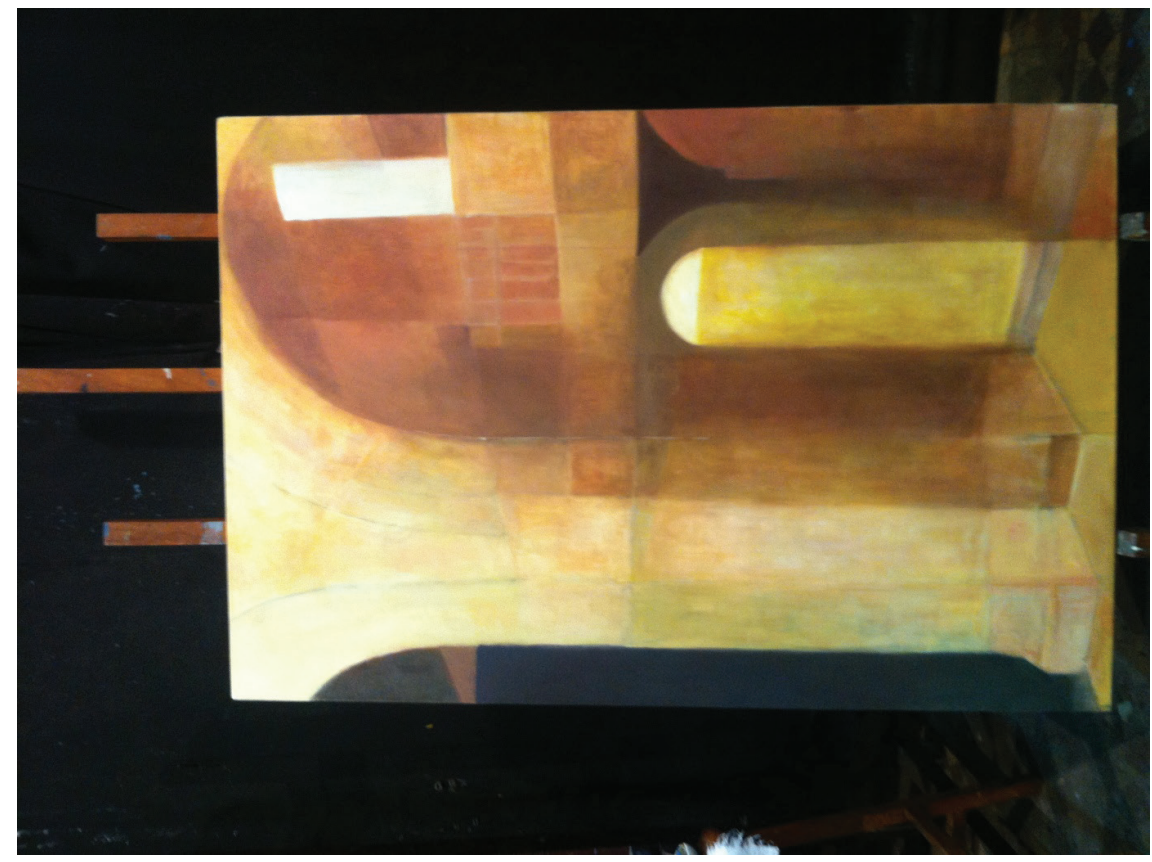

A pintura do cenáculo se refere ao espaço físico onde Jesus tomou sua última ceia com os seus discípulos, no Monte Sião em Jerusalém.

4 OTTO, Rudolf. O Sagrado: um estudo do elemento não-racional na idéia do divino e a sua relação com o racional. (tradução: Prócoro Velasquez Filho). São Bernardo do Campo: Imprensa Metodista, 1985. 
A abertura que representa o acesso, a "porta", traz à alma uma proposição enigmática através de uma luz com duplo sentido, uma nefasta da morte onde a finitude se materializa e a outra profética que através da estreita abertura traz consigo a transcendência do Cristo ressurreto numa realidade eterna.

Nesse momento da expressão pictórica, entendo a "presença" do sagrado que nos arrebata, numa satisfação inexplicável. Tillich também discute a relação entre o estilo artístico e a religião. Cada estilo indica a auto interpretação do ser humano em resposta à questão do significado último da vida. Em cada expressão artística, é possível identificar a preocupação suprema, pois o absoluto não se restringe a formas particulares de coisas e experiências". Uma confissão da esperança, como o apóstolo Paulo cita em Romanos 5: 3-4 "E não somente isto, mas também nos gloriamos nas tribulações; sabendo que a tribulação produz a paciência, e a paciência a experiência, e a experiência a esperança".

Segundo Tillich "a produção artística não precisa ter um conteúdo religioso para falar de verdades religiosas". ${ }^{5}$

Assim se deu no quadro "Cenáculo", "a verdade religiosa" se dá através do "clima " do ar e da luz que envolve o ambiente de morte e ressurreição onde a cruz, símbolo da vitória de Jesus Cristo sobre a morte, não está presente na pintura, mas através das verticais e horizontais da estrutura com as tensões do diagrama de força.

De acordo com Tillich há uma aproximação entre a experiência estética e a religiosa pois as duas são capazes de ir na profundidade do ser e de revelar aspectos que fogem a uma estrutura racional. Para Tillich havia uma relação de parentesco entre religião e arte, porque ambas buscam dar respostas às questões essenciais da vida.

\section{Conclusão}

Finalizando essa conversa sobre Arte e Sagrado, já sinto saudade desse período que reservei para refletir e buscar compreender esse mistério profundo que nos envolve tantos nos dias maus como nos dias

\footnotetext{
Experiência estética e religiosa, uma leitura sobre arte moderna em Paul Tillich (Severina coletivo) https://coletivoseverina.wordpress.com/2016/02/24/experiencia-estetica -e-experiencia-religiosa-uma-leitura-sobre-arte-moderna-em-paul-tillich/ acessado em 26/06/2017.
} 
bons! Se deixar tocar pelo sagrado, é "se lançar" nos braços da Fé e aceitar a razão que dela é conhecida.

Na minha experiência, o Sagrado é uma condição a priore, porque abre meus olhos para que a Fé e a Arte possam andar juntas sem limitar a compreensão humana e tão pouco aquela dos antigos, "Foi porque tiveram essa fé que grandes homens de Deus receberam o testemunho da aprovação de Deus" (Hebreus 11:2).

"Nem olhos viram, nem ouvidos ouviram, nem jamais penetrou em coração humano o que Deus tem preparado para aqueles que o amam." 1 Coríntios 2:9. 